\title{
EPHEMERAL IDENTITY IN EDEN Robinson's MONKEY BEACH
}

\author{
Sonu Purhar, University of Victoria
}

\begin{abstract}
Eden Robinson's Monkey Beach addresses issues related to race, historic oppression, and the clash between cultures in a coming-of-age ghost story set in the Haisla community of Kitimaat, British Columbia. Literary scholars have discussed the difficulty of the novel's heroine, Lisamarie Hill, in reconciling her First Nations and West Coast identities, particularly when she acquires the unique ability to converse with the spirit world; however, the implications of this ability within both her inherited and adopted cultures have largely been ignored. In the context of her Haisla heritage Lisamarie's powers are shamanistic, imbuing her with great responsibility and control within her band's society-yet she cannot embrace her gift within the contemporary Eurocentric society that refuses to accept its existence. Though Lisamarie eventually gains control over her powers, the historic and continued oppression of her culture by West Coast society challenges her capability to maintain this connection in the modern world.
\end{abstract}

I $\mathrm{n}$ her novel Monkey Beach, Eden Robinson initiates a literary and political discourse about the status of First Nations peoples in contemporary British Columbia. Her depiction of a Haisla family living in present-day Kitamaat exposes the difficulties faced by First Nations bands in preserving their traditions, values, and social mores under the dominating influence of Canada's West Coast society, which, for the purposes of this paper, is identified as the collective acceptance of Euro-Canadian history and belief systems. Robinson frames these political concerns in a coming-of-age narrative that follows the 


\section{Ephemeral Identity in Eden Robinson's \\ Monkey Beach}

struggles of a young Haisla woman, Lisamarie Hill, as she attempts to reconcile the ideologies of her modern Canadian upbringing with the often discordant beliefs of her First Nations heritage. Lisamarie's search for a cohesive identity is further complicated by the unexplained appearance of ghosts and monsters that only she can see, situating the tensions between her Western and First Nations backgrounds within a specific, identifiable conflict.

Previous critics have noted the juxtaposition of Lisamarie's proximity to, and alienation from, the Haisla spiritual world, particularly in the context of her family's "adopted" West Coast culture, which is generally dismissive of ghosts and monsters. Ella Soper-Jones reflects on the political influences that have led to this paradox, arguing that the Canadian government's history of colonizing Indigenous territories has threatened the utility and worth of Haisla and other First Nations traditions ${ }^{1}$. Jodey Castricano counters that Lisamarie's relationship with the spirit world allows her to transgress this history of abuse and reconnect with her heritage, ${ }^{2}$ though she must contend with North American ideologies that consider spiritual practices dysfunctional. ${ }^{3}$ Finally, Jennifer Andrews notes that the discordant mood of the novel stresses the "... often jarring juxtapositions of Native and non-Native viewpoints." and other scholars have addressed Lisamarie's difficulty in reconciling her First Nations and Western cultures, the implications of their "juxtaposed viewpoints" for understanding Lisamarie's spiritual gift have largely been ignored.

Considered from a Haisla perspective, her prophetic visions and interactions with spirits indicate that Lisamarie is a shaman, a figure central to Haisla society who carries tremendous power and control. The novel's Western-minded characters, conversely, regard her "gift" with suspicion, and attribute her visions to pathological constructs

\footnotetext{
1 Ella Soper-Jones, "The Fate of the Oolichan: Prospects of Eco-Cultural Restoration in Eden Robinson's Monkey Beach," The Journal of Commonwealth Literature 44, no. 2 (2009): 28.

2 Jodey Castricano, "Learning to Talk with Ghosts: Canadian Gothic and the Poetics of Haunting in Eden Robinson's Monkey Beach," University of Toronto Quarterly 75, no. 2 (2006): 802.

3 Ibid., 805.

4 Jennifer Andrews, "Native Canadian Gothic Refigured: Reading Eden Robinson's Monkey Beach," Essays on Canadian Writing 73 (2001): 10.
} 
like hallucinations. Thanks to the guidance and validation provided by her grandmother, Ma-ma-oo, Lisamarie gains control within the spirit world, progressing from helplessness and vulnerability to selfreliance and authority. However, the disparity between her adopted and inherited cultures continues to dominate. Evidently, Lisamarie cannot sustain her relationship to the spirit realm within a society that refuses to accept its existence; she must either suppress her gift or risk alienation and persecution. Though Lisamarie eventually gains control over her shamanistic abilities, thereby reconnecting with her First Nations heritage, the historic and continued suppression of her culture by West Coast society challenges her ability to maintain this connection in the modern world.

Monkey Beach is set in the small, coastal village of Kitamaat in western B.C., home to the province's Haisla community. The story begins in medias res as the narrator, Lisamarie Hill, anxiously awaits news about her brother, Jimmy, whose fishing boat has disappeared off the coast of Prince Rupert. The novel is composed of a series of flashbacks, beginning in Lisamarie's childhood when she experiences her first encounters and interactions with the spirit world. Her grandmother tells her that she has inherited a rare and special gift from her First Nations culture, but Lisamarie soon realizes that within the greater Western society her "gift" is considered pathological. This dichotomy threatens Lisamarie's sense of identity, gradually leading her down a harmful path of drugs, violence, and death as she struggles to both understand and control her spiritual visions.

Robinson's choice of setting arises in part from her Haisla roots but also situates the provincial government's subordination of the First Nations peoples within a specific community. Early in the novel, Robinson alludes to the enduring reminders to the Haisla peoples of early Canadian-European contact and its influence on the band's loss of cultural identity: Lisamarie describes how Hudson's Bay traders inadvertently renamed the Haisla land, referring to it as "Kitamaat" rather than its true name, Haisla. ${ }^{5}$ In later years, says Soper-Jones, ethnographers studying Haisla and other tribes along B.C.'s northwest coast grouped the various bands under the name "Kwakiutl," falsely creating a cultural homogeneity among them. ${ }^{6}$ Other influences were

5 Eden Robinson, Monkey Beach (Toronto: Knopf Canada, 2000), 4.

6 Soper-Jones, "Fate of the Oolichan," 18. 


\section{Ephemeral Identity in Eden Robinson's \\ Monkey Beach}

more overtly political. The Indian Act of 1876, for example, established a strict policy for governing relations between First Nations peoples and the Canadian government; Robert Muckle notes that many Indigenous peoples opposed the legislation, believing that it promoted inequality and poverty among bands and functioned to "destroy First Nations' cultures." The Act gave the federal government control over indigenous elections of council, use of reserves, and educational reform. Later versions also prohibited potlatch ceremonies, claiming they were a detriment to the nation's economic expansion. ${ }^{8}$ These, and additional statutes, effectively stripped First Nations bands of their political and social power, and, as Soper-Jones points out, contributed to the growing irrelevance in Canada of Aboriginal traditions and identities. ${ }^{9}$

Though the impact of Western oppression is a running theme in Monkey Beach, Robinson makes specific reference to the harmful effects of residential schools. Muckle claims that these governmentrun institutions were just as destructive to First Nations identity as the appropriation of their land: "The policy of most residential schools was first to break the children of all cultural ties . . . and then to educate them in Christian and Euro-Canadian ways." ${ }^{\prime 10}$ By conditioning Indigenous youth to discount basic cultural knowledge such as language and social norms, school officials contributed directly to the disintegration of First Nations culture. In addition, the institutions were notorious for physical, sexual, and emotional abuse, reports of which first appeared in the late nineteenth century and continued throughout the twentieth. Yet despite the contention surrounding the abuse, the last school in B.C. did not close until 1984. ${ }^{11}$ Robinson demonstrates the effects of the residential school system in Monkey Beach most saliently through the characters of Mick and Trudy, Lisamarie's aunt and uncle, both of whom were sent to residential school and suffered abuse during their time there. Lisamarie's cousin Tab summarizes the lasting damage inflicted by the institution when she says to Lisamarie, "You're really lucky that

7 Robert James Muckle, The First Nations of British Columbia: an Anthropological Survey (Vancouver: UBC Press, 1998), 85.

8 Muckle, Anthropological Survey, 85.

9 Soper-Jones, "Fate of the Oolichan," 15.

10 Muckle, Anthropological Survey, 81

11 Ibid., 82. 
your dad was too young to go to rez school. Aunt Kate, too, because she was married. Just Mick and my mom went and it fucked them up. ${ }^{12}$ Robinson incorporates these historical realities into her story to establish the long-term impact of Euro-Canadian colonialism on individuals as well as large groups in indigenous society. Her decision to relate the story through the perspective of a modern Haisla woman further emphasizes that these effects have travelled through generations, affecting not only those who experienced the encounters firsthand but also successive generations who must live with the emotional and social repercussions.

The lingering effects on the Hill family of governmental oppression and residential school exemplify the struggle for identity inherent in the Haisla community. Though Lisamarie's family has been traumatized by the damage to their culture, they must assimilate into British Columbia's western-dominated society or risk ostracization. The consequences of dissent are demonstrated most provocatively when Lisamarie challenges an in-class textual reference to cannibalism among Aboriginal bands in northwest B.C., to which her teacher responds by sending her to the principal's office. ${ }^{13}$ The exchange's setting - a Canadian educational institution - reinforces the tacit obligation for minorities to adopt a collective Western history, and Lisamarie's punishment indicates that alternative views will not be tolerated.

The risks of non-conformity are especially severe for Lisamarie, whose struggle to form a coherent identity is complicated by her contact with ghosts and monsters. Lisamarie's ignorance of Haisla ways and her desire to be "normal" initially lead her to doubt her visions. Early in the novel when she sees the b'gwus at Monkey Beach, her first reaction is scepticism: "Doubt began to set in: it had happened so fast and had been so brief, I wondered if I'd just imagined the whole thing." ${ }^{14}$ She also refers to the b'gwus as a "man," indicating her reluctance to believe that she has seen a mythical creature. She chooses not to tell anyone of the sighting because she knows they would not believe her: "I cringed when I imagined myself telling people I'd seen a b'gwus. They'd snicker about it the way they did

12 Robinson, Monkey Beach, 254.

13 Ibid., 69.

14 Ibid., 16. 


\section{Ephemeral Identity in Eden Robinson's \\ Monkey Beach}

when Ma-ma-oo insisted they were real." ${ }^{\prime 5}$ Lisamarie's reaction arises from her knowledge that North Americans are generally disbelieving of mythical beasts. In Western conceptions, the Sasquatch is treated more as a figure of popular culture than spirituality, which is illustrated in the novel by Jimmy's eagerness to capture the b'gwus on film so he can sell the photo to a weekly tabloid. ${ }^{16}$

Since the story is told from Lisamarie's perspective, her uncertainty about the validity of her visions extends to the reader. Her encounters with the little red-haired man, for example, are initially open to doubt. She first sees him when she is a child, at an age when she might be expected to invent an imaginary playmate. The next time he appears he awakens her in the middle of the night, puts a finger to his lips as if to warn her to keep silent, and then melts back into the bedroom wall. ${ }^{17}$ When Lisamarie tells her mother, Gladys, about the episode, Gladys insists that it was a nightmare, dismissing the possibility that the little man could be real and, in so doing, instilling doubt in both Lisamarie and the reader as to whether he was really there. Lisamarie's wariness of the little man and the b'gwus also encapsulates a fear of the unknown: she has been conditioned to doubt the existence of ghosts and monsters, and she fears that since no one else can see the apparitions she cannot trust her own mind.

Lisamarie's instinct to deny the reality of the spirit world is a product of her environment. Her exposure to this world occurs in the context of a community that has learned to renounce its existence. Her parents refuse to entertain the possibility that her visions are legitimate, choosing instead to adopt the prevailing attitudes of the society into which they have assimilated. When Jimmy begs his father to take the family to Monkey Beach so he can see a b'gwus, his father insists that the b'gwus is make-believe. ${ }^{18}$ Jimmy points out that Ma-ma-oo believes in the creature, but his father counters, "Your grandmother thinks the people on TV are real." 19 His scornful response not only dismisses the existence of such a creature, but also challenges Ma-ma-oo's credibility as a Haisla elder and further calls attention to the tensions between Haisla and Western belief systems.

15 Ibid., 17.

16 Ibid.,10.

17 Ibid., 18.

18 Ibid., 10.

19 Ibid. 
Gladys is just as resolute as her husband in rejecting the spirit realm. After Jimmy's disappearance, Lisamarie insists that the crows were trying to give her a sign as to his whereabouts. Her mother refuses to take the exchange seriously, saying, "Clearly a sign, Lisa ... that you need Prozac." ${ }^{20}$ Later in the novel, however, Ma-ma-oo reveals that Gladys once also showed signs of Lisamarie's gift. When Lisamarie protests that her mother never gave any indication of seeing spirits, Ma-ma-oo says, "She doesn't tell you when she sees things. Or she's forgotten how. Or she ignores it." ${ }^{21}$ Like Lisamarie, Gladys is aware that to survive in modern Canadian society she must suppress those parts of her culture that oppose conventional belief systems. This further suggests that Gladys's refusal to acknowledge the apparitions is in fact an attempt to conceal her daughter's abilities to protect her from exclusion.

When Lisamarie's visions progress to vivid nightmares and bouts of sleepwalking, her parents send her for neurological, physical, and finally psychological testing - a scientifically-oriented response associated with Western rather than First Nations attitudes. The psychiatrist, Ms. Jenkins, opines that Lisamarie's "hallucinations" are a cerebral reaction to the deaths of her loved ones. ${ }^{22}$ Castricano argues that Ms. Jenkins' refusal to consider the spiritual implications of Lisamarie's visions is spurred by the desire to impose her own worldview. ${ }^{23}$ However, the monstrous "thing" clinging to Ms. Jenkins throughout the session calls her credibility into question: its attachment to her symbolizes the ignorance and bias of the dominant white culture that she represents, a prejudice of which she is both literally and figuratively unaware. But the "thing" also attaches itself to Lisamarie and instructs her to retract her belief in ghosts. ${ }^{24}$ The episode provides an early indication of the spirits' attempts to protect Lisamarie, in this case from suffering persecution. Indeed, when Lisamarie follows the monster's instructions and discounts her visions, Ms. Jenkins expresses approval and tells Lisamarie that she will "be back to normal in no time." ${ }^{25}$ Her use of the phrase "back to

20 Ibid., 3.

21 Ibid., 154.

22 Ibid., 273.

23 Castricano, "Learning to Talk with Ghosts," 805

24 Robinson, Monkey Beach, 274.

25 Ibid., 274. 


\section{Ephemeral Identity in Eden Robinson's \\ Monkey Beach}

normal" emphasizes her opinion that Lisamarie's abilities, in a Western context, are considered abnormal - perhaps even pathological.

Ms. Jenkins' readiness to attribute Lisamarie's visions to mental disturbance stems from what Castricano refers to as the "Freudiandominated western tradition" that has recently become ingrained in the cultural psyche. ${ }^{26}$ Specifically, Castricano notes, "The history of psychology - from Mesmer to Freud - tells us of concentrated efforts to keep the study of the mind an occult-free zone and to repudiate all things 'mystical." ${ }^{27}$ Freud's theories of psychopathology came to dominate social, ethnological, and anthropological realms in the Western world during the same period in which Euro-Canadian imperialism was depriving Indigenous peoples of their rights. Particularly applicable to Robinson's novel is Totem and Taboo (1913), in which Freud draws parallels between the mental lives of "primitive" cultures and neurotics. Edwin Wallace attests to the wide-ranging impact of these theories in western societies, noting that "[Freud's] ideas on ... spirits as projections, on magic as wish fulfillment and omnipotence of thought, and on ambivalence toward the dead [were] favourably received." ${ }^{28}$ The continued prevalence of Freud's constructs in modern society make them especially relevant in providing a Western "diagnosis" of Lisamarie's spiritual interactions, especially since her physical reactions conform to the "symptoms" Freud describes: "The most pronounced psychological expressions which point to a deep-seated disturbance are hallucinations and delusions ... the patient hears, sees, or feels something that is not perceived by anyone else." ${ }^{29}$ This concept accounts for Ms. Jenkins' assumption that Lisamarie's visions are hallucinatory; since no one else sees the spirits, she assumes Lisamarie is experiencing "deep-seated disturbance."

Freud also posits that nightmares are mental expressions of traumatic experience, ${ }^{30}$ which suggests that Lisamarie's nightmares derive from traumatic events such as the deaths of Mick and Ma-maoo, her rape, and Jimmy's disappearance. The stress creates mental

26 Castricano, "Learning to Talk with Ghosts," 805.

27 Ibid., 803.

28 Edwin R. Wallace, Freud and Anthropology: A History and Reappraisal (New York: International University Press, 1983), 169.

29 Sigmund Freud, Delusion and Dream and Other Essays, ed. Philip Rieff (Boston: Beach Press, 1956), 116.

30 Robert Bocock, Freud and Modern Society (Middlesex: Nelson, 1976), 111. 
turmoil that she represses in waking life but is unable to control during sleep. In Totem and Taboo Freud conjectures that ghosts are "nothing but the projections of primitive man's emotional impulses." ${ }^{1}$ He discusses further in Delusions and Dreams the danger of primitive religions that encourage beliefs in spirits, apparitions, and returning souls. ${ }^{32}$ From a Freudian perspective, then, Haisla beliefs in the spirit realm are actually damaging to Lisamarie, since they falsely support the validity of her visions and thereby lead her further into pathology. Theories such as Freud's that discount mysticism and promote scientific analysis have become embedded in contemporary society, which explains why the novel's western characters so readily attribute Lisamarie's visions to physical or mental disturbance.

At the same time that Lisamarie must hide her gift to conform to Euro-Canadian societal norms, she must also overcome her ignorance about Haisla culture to maintain control of a spirit world that refuses to be ignored. As Soper-Jones points out, Lisamarie acquires her abilities without the knowledge that would help her make sense of them and use them responsibly. ${ }^{33}$ She does, however, benefit from the wisdom of her grandmother, Ma-ma-oo, who familiarizes Lisamarie with the spirit realm and teaches her to see the value in sources like myths and legends. Andrews notes that Ma-ma-oo's role within the novel is to not only educate Lisamarie about Haisla spiritual lore, but also to help her situate that world within her own life. ${ }^{34}$ At a basic level, Ma-ma-oo teaches her granddaughter practical information, such as how to use tobacco, roots, and incense to communicate with and appease spirits, ${ }^{35}$ and how to interpret the calls of birds ${ }^{36}$ More importantly, she models to Lisamarie the value of her gift. For example, she brings Lisamarie to Octopus Beach and broaches a conversation with her late husband. When Lisamarie protests, "But he's not here," Ma-ma-oo responds, "Yes he is . . . you just can't see him because he's dead." ${ }^{77}$ The interaction shows Lisamarie that while

31 Dr. A. A. Brill, "Introduction," in The Basic Writings of Sigmund Freud, by Sigmund Freud (New York: Random House, 1938), 878.

32 Freud, Delusion and Dreams, 104.

33 Soper-Jones, "Fate of the Oolichan," 24.

34 Andrews, "Native Canadian Gothic," 14.

35 Robinson, Monkey Beach, 151-2.

36 Ibid., 264.

37 Ibid., 79. 


\section{Ephemeral Identity in Eden Robinson's \\ Monkey Beach}

conversing with ghosts is considered illogical in her Western life, it is accepted and even encouraged in Haisla tradition. Ma-ma-oo also teaches Lisamarie that the spirit world should not be feared, as when she says, "You don't have to be scared of things you don't understand. They're only ghosts." ${ }^{\text {" }} 3$ Ma-ma-oo's lessons introduce the possibility that the spirit world is real, a notion that the novel's Western-oriented characters persistently ridicule. ${ }^{39}$ While Ma-maoo encourages Lisamarie to reconnect with her Haisla roots, she also warns her that to fully understand Haisla lore, Lisamarie must learn to speak the language. ${ }^{40}$ Lisamarie's frustration at her slow progress in learning Haisla revisits the cultural divide between her native and adopted cultures, and reflects a constant awareness within the text of the distance and exclusion between these societies. ${ }^{41}$

Though Ma-ma-oo provides a basic education in Haisla culture, both Lisamarie and the reader are denied crucial details about the band's social structure and traditions, making it difficult to discern Lisamarie's role within the spirit world. This confusion results primarily from the lack of available information about Haisla society: the band is protective of their customs and Robinson herself said that she was uncomfortable elaborating on specific traditions in the novel. ${ }^{42}$ Adding to the problem of cultural ambiguity is that there is only one published report of Haisla social life, Ivan Alexis Lopatin's 1945 anthropological account Social Life and Religion of the Indians in Kitimat, British Columbia. Though more than half a century old, Lopatin's report is nevertheless the most comprehensive picture we have of traditional Haisla society. Correspondingly, his observations of the social organization and customs shed light on the implications of Lisamarie's abilities within a Haisla context. Specifically, Lopatin's account suggests that Lisamarie is a shaman, a cultural medium who acts as a liaison between the living and the spirit realm-a role that carries inherent responsibilities to the well-being of the community and therefore cannot be easily denied.

In opposition to Freudian theories that "spirits" are actually imagined projections, Haisla communities believe that spirits are not

38 Ibid., 265.

39 Castricano, "Learning to Talk with Ghosts," 808.

40 Robinson, Monkey Beach, 211.

41 Andrews, "Native Canadian Gothic," 15.

42 Soper-Jones, "Fate of the Oolichan," 17. 
only real but are actively involved in daily life. ${ }^{43}$ According to Lopatin, Haisla people regard most spirits as malicious and attribute them with causing all disease and distress in the world. ${ }^{44}$ If not for these creatures, people would live forever ${ }^{45}$ Shamans protect the rest of the community from these spirits, thereby ensuring their continued survival. ${ }^{46}$ They are also able to foretell the future, ${ }^{47}$ an ability that manifests itself in Lisamarie through the visions that she calls "death sendings," which prophesy future deaths. Such abilities are revealed in shamans when a spirit enters the individual's body and shows itself through some type of nervous disorder. ${ }^{48}$ In Lisamarie's case, her gift is physically revealed by her sleepwalking. During one of her early bouts of somnambulism, she sees a neighbourhood house full of ghosts and takes it to mean that one of the residents will die. ${ }^{49}$ Later, in the hospital, she sleepwalks again and sees that " $t$ t]he hallways were filled with ghosts." ${ }^{0}$ Interestingly, Lopatin notes that the criterion of a visible bodily reaction suggests that a person most suitable for shamanistic practice is one who suffers from mental disturbance. ${ }^{51}$ This reiterates the divergence in cultural perspectives: while Western views of pathology consider mental affliction to rob the individual of control, Haisla believe that the same individual has the potential for great power. Finally, Lopatin observes that shamanistic gifts are transmitted primarily through genetics, ${ }^{52}$ which is evidenced in the novel by the fact that Lisamarie's grandmother and mother both show traces of these abilities.

Lopatin also observes in his field study that shamans are guided by a spirit patron, or ashuta, who helps them navigate the spirit world and the land of the dead. ${ }^{53}$ It becomes increasingly apparent throughout Monkey Beach that Lisamarie's ashuta is the little red-haired man. His

43 Ivan Alexis Lopatin, Social Life and Religion of the Indians in Kitimat, British Columbia (Los Angeles: S. California Press, 1945), 60.

44 Lopatin, Social Life, 63.

45 Ibid., 73.

46 Ibid., 63.

47 Ibid., 74.

48 Lopatin, Social Life, 64.

49 Robinson, Monkey Beach, 266.

50 Ibid., 267.

51 Lopatin, Social Life, 64.

52 Ibid., 65.

53 Ibid., 66. 


\section{Ephemeral Identity in Eden Robinson's \\ Monkey Beach}

first appearances suggest he is nothing more than a ghostly apparition: "He became a variation of the monster under the bed or the thing in the closet, a nightmare that faded with morning." ${ }^{54}$ However, his recurring presence and the deaths that occur after Lisamarie sees him imply that his role is more important. The first indication that he is a prophecy of death comes the night before a flock of hawks massacre the Hill family's chickens: the little man appears in Lisamarie's room $^{55}$ and the next day she is met with the gruesome scene in the backyard. ${ }^{56}$ When she and her friends attempt voodoo magic using a "how-to" book, the little man appears in her room that same night". .. hanging by his neck from a yellow rope, smiling at [Lisamarie] as he swung back and forth. ${ }^{57}$ The scene is a reminder to Lisamarie of the dangers of treating the spirit world lightly, especially by a shaman whose responsibility is to pacify the spirits to avoid retaliation. Lisamarie and the reader receive affirmation of the little man's role as her spirit guide when Ma-ma-oo tells her that in Haisla lore, the redhaired man is a guide of medicine men. ${ }^{58}$ While Lisamarie initially fears the little man, she soon realizes that she needs him to guide her through the spirit world. She also comes to understand that he is there to help, not harm, her: "Even after he disappeared, I could feel where his hands had touched me, and I knew he'd been trying to comfort me." ${ }^{59}$ She compares him to Christopher Robin's Pooh Bear and Jackie Piper's Puff the Magic Dragon, ${ }^{60}$ which likens him to a companion or sidekick that is inseparable from its owner.

Because of the threats inherent in the spirit world, shamans must constantly be on alert. ${ }^{61}$ Haisla lore warns that if shamans do not learn to control their powers, the spirit world will take over and wreak havoc. ${ }^{62}$ There are several instances in Monkey Beach of the spirits toying with Lisamarie, often driving her dangerously close to

54 Robinson, Monkey Beach, 27.

55 Ibid., 27.

56 Ibid., 37.

57 Ibid., 222.

58 Ibid., 152.

59 Ibid., 132.

60 Ibid., 131-2.

61 Lopatin, Social Life, 79.

62 Ibid., 79. 
destruction. For example, after her rape, she is both frightened and angered to hear voices in the woods calling her name and taunting her: "Bring us meat ... and we'll hurt him." ${ }^{63}$ After a night of partying, she is visited by the ghost of her cousin $\mathrm{Tab}^{64}$ and fears she is dead, but later finds out that Tab is still alive.$^{65}$ Near the end of the novel, when Lisamarie demands that the monstrous "thing" show her what happened to Jimmy, it sends her an image of his death and the anguish nearly leads her to suicide. ${ }^{66}$

Though Lisamarie gradually familiarizes herself with the requirements of her shamanistic role, she remains wary of her gift, particularly her inability to integrate it into her North American lifestyle. That changes, however, when Ma-ma-oo dies in a house fire. The day before she dies, Ma-ma-oo surprises Lisamarie by revealing that she can see the spirits that fill her house. ${ }^{67}$ Though Lisamarie is no longer terrified of her ghostly visions, she remains uneasy of them: "... I couldn't see them clearly and didn't want to." ${ }^{68}$ Later, she hears the ghosts but continues to ignore them: "No one's here, I told myself .. I I am alone, and I don't see anything ." ${ }^{69}$ When Ma-ma-oo dies that night, Lisamarie is tormented by the thought that she could have prevented her grandmother's death had she acknowledged the spirits instead of dismissing them: "I could have saved her. If I had listened to my gift instead of ignoring it, I could have saved her." ${ }^{70}$ For the first time, she fully appreciates the consequences of rejecting her gift, and realizes that she must sacrifice "normality" to embrace this central part of her identity. Ma-ma-oo's death leads Lisamarie to understand that interacting with spirits is, as Castricano describes, "less about pathology than it is about spirituality and survival." ${ }^{71}$

Once she has accepted the irrefutable reality of the spirit realm, Lisamarie begins to express comfort at knowing there are magical beings in the world. Andrews explains that after Lisamarie is forced

63 Robinson, Monkey Beach, 262.
64 Ibid., 301.
65 Ibid., 305.
66 Ibid., 370.
67 Ibid., 289.
68 Ibid., 289.
69 Ibid., 291.
70 Ibid., 294.
71 Castricano, "Learning to Talk with Ghosts," 806. 


\section{Ephemeral Identity in Eden Robinson's \\ Monkey Beach}

to acknowledges the spirit realm and her place within it, she comes to realize that it is a place ". . . in which monsters exist but are not necessarily destructive." ${ }^{\prime 2} \mathrm{Her}$ connection to this world strengthens over the course of the novel, and is revealed by scenes that illustrate her adoption of Haisla customs. After Uncle Mick dies, for example, she cuts off all of her hair, adhering to Haisla mourning rituals. ${ }^{73}$ When she is raped by her friend Cheese, she draws on Haisla spiritual practices to seek revenge on her tormenter, burning her clothes along with an animal sacrifice while thinking, "I wished he would burn. I wished him pain and unending agony." "

Lisamarie demonstrates not only an increased understanding of her culture's spiritual realm but also an eventual mastery of it. When her friend Frank tells her that he saw Pooch after he shot himself, Lisamarie explains that the vision was a death sending and reassures a shaken Frank that the apparition is "nothing to worry about." "75 Her authority is substantiated by her "lessons" within the text on communicating with the spirit world, which further unsettle reader notions of what is "real." One such lesson proclaims that an altered state of sleep is the best way to contact the dead. ${ }^{76}$ The passage opposes Ms. Jenkins and her parents' dismissal of her dreams and late-night visions by revealing the trance-like state between sleep and consciousness as a portal between the dead and the living. She later proposes that this portal can be accessed through meditative practices, ${ }^{77}$ which points to the irony of a popular North American trend facilitating contact with the ghostly realm that this society denies. In the same lesson, Lisamarie notes that "[a]ny fear, doubt or disbelief will hinder your efforts, ${ }^{178}$ suggesting that scepticism arises solely from a stubborn refusal to believe. The lessons are interspersed with passages reminiscent of medical texts, which further emphasize the distance between Haisla and Western notions of the "real." One

72 Andrews, "Native Canadian Gothic," 9.

73 Robinson, Monkey Beach, 175.

74 Ibid., 262.

75 Ibid., 313.

76 Ibid., 139.

77 Ibid., 212.

78 Ibid., 212. 
passage describes the structure of the heart ${ }^{79}$ while another explains the biological impetus of a heart attack. ${ }^{80}$ These sections are presented in a clear, scientific manner that juxtaposes Lisamarie's tutorials on contacting the dead, calling attention to the unresolved disparity between Western and Haisla mindsets.

Lisamarie most fully embraces her power when the novel draws to a close. In an act of ritual sacrifice, she offers her blood to the tree spirits so they will show her what happened to Jimmy. ${ }^{81}$ Immediately afterward she enters the Land of the Dead, from which her family's ghosts send her back to Monkey Beach. When she awakens alone on the beach, Lisamarie hears a faint echo: "Close, very close, a b'gwus howls - not quite human, not quite wolf, but something in between." 82 The mutability of this creature-part-human and part-monstersignifies Lisamarie's own dilemma. She has learned that she cannot integrate her role as shaman into her contemporary lifestyle. Her West Coast and First Nations identities are too much at odds to be successfully united. The novel's ending leaves Lisamarie sprawled on the beach, caught between two worlds-but Robinson has left her choice between them unclear.

Castricano argues that once Lisamarie learns to harness her magical abilities, her resulting connection to the spirit world allows her to recapture the traditions of her Haisla culture in spite of its negation by European contact. ${ }^{83}$ Indeed, as the novel progresses Lisamarie's response to this realm evolves from fear and doubt to acceptance and understanding, revealing her success in rising above the dominant culture to rediscover her First Nations heritage. But the narrative also implies that reconciliation is not possible. To exist peaceably in North American society, Lisamarie must conceal her gift or risk persecution. In fact, Robinson calls into question whether it is even possible for Lisamarie to return to old Haisla ways: the Kitimaat in Monkey Beach has become so westernized that most community members refuse to acknowledge traditional folklore and customs, and even elders like Ma-ma-oo claim that the old ways "just hold you back." ${ }^{4}$ Throughout

79 Ibid., 192.

80 Ibid., 268.

81 Ibid., 365.

82 Ibid., 374.

83 Castricano, "Learning to Talk with Ghosts," 802.

84 Robinson, Monkey Beach, 153. 


\section{Ephemeral Identity in Eden Robinson's \\ Monkey Beach}

the text, Robinson speculates that the disappearance of Haisla culture is a growing threat, exacerbated by band members assimilating into a modern North American society that has made it difficult to preserve cultural traditions. Though Lisamarie does succeed in reconnecting with her roots, the question remains as to whether she can regain her place in traditional Haisla society or if western suppression has closed forever the door on the Haisla past.

\section{Bibliography}

Andrews, Jennifer. "Native Canadian Gothic Refigured: Reading Eden Robinson's Monkey Beach." Essays on Canadian Writing 73 (2001): 1-24.

Bocock, Robert. Freud and Modern Society. Middlesex: Nelson, 1976.

Brill, Dr. A.A. Introduction to The Basic Writings of Sigmund Freud, by Sigmund Freud, 3-32. New York: Random House, 1938.

Castricano, Jodey. "Learning to Talk With Ghosts: Canadian Gothic and the Poetics of Hauntingin Eden Robinson's Monkey Beach." University of Toronto Quarterly 75.2 (2006): 801-813.

Freud, Sigmund. Delusion and Dream and Other Essays. Ed. Philip Rieff. Boston: Beach Press, 1956.

Lopatin, Ivan Alexis. Social Life and Religion of the Indians in Kitimat, British Columbia. Los Angeles: S. California Press, 1945.

Muckle, Robert James. The First Nations of British Columbia: An Anthropological Survey.Vancouver: UBC Press, 1998.

Robinson, Eden. Monkey Beach. Toronto: Alfred A. Knopf Canada, 2000.

Soper-Jones, Ella. "The Fate of the Oolichan: Prospects of Eco- 
Cultural Restoration in Eden Robinson's Monkey Beach." The Journal of Commonwealth Literature 44.2 (2009): 15-33.

Wallace, Edwin R. Freud and Anthropology: A History and Reappraisal. New York: International University Press, 1983. 